\title{
Multivitamin and Protein Supplement Use Is Associated With Positive Mood States and Health Behaviors in US Military and Coast Guard Personnel
}

\author{
Krista G. Austin, PhD, *广 Susan M. McGraw, BS, * and Harris R. Lieberman, PhD*
}

\begin{abstract}
Approximately 60\% of Armed Forces personnel regularly consume dietary supplements (DSs). We investigated the association of mood and health behaviors with multiple classes of DSs in military and Coast Guard personnel $(\mathrm{N}=5536)$. Participants completed a survey of DS use and the Quick Mood Scale to assess mood domains of wakefuldrowsiness, relaxed-anxious, cheerful-depressed, friendly-aggression, clearheaded-confused, and well coordinated-clumsy. Supplements were categorized as multivitamin/minerals (MVM), individual vitamin/minerals, protein/amino acid supplements (PS), combination products (C), herbals $(\mathrm{H})$, purported steroid analogs, (S) and other (O). One-way analyses of covariance assessed associations of DSs and perceived health behavior with mood controlling for age. Logistic regression determined associations between DS use and health behavior. Users of MVM and PS reported feeling significantly $(P<0.05)$ more awake, relaxed, cheerful, clearheaded, and coordinated. Participants using PS and S reported feeling less friendly (more aggressive, $P<0.02$ ). Users of MVM and PS were more likely to report their general health, eating habits, and fitness level as excellent/good $(P<0.05)$. Participants reporting health behaviors as excellent/good were more $(P<0.01)$ awake, relaxed, cheerful, friendly, clearheaded, and coordinated. As no known biological mechanisms can explain such diverse effects of MVM and PS use on multiple mood states, health, eating habits, and fitness, we hypothesize these associations are not causal, and DS intake does not alter these parameters per se. Preexisting differences in mood and other health-related behaviors and outcomes between users versus nonusers of DSs could be a confounding factor in studies of DSs.
\end{abstract}

Key Words: amino acids, steroids, aggressive, depression, alertness, Army, Air Force, herbal

(J Clin Psychopharmacol 2014;34: 595-601)

$\mathrm{D}$ ietary supplements (DSs) are considered by civilian and military personnel to be an effective method for improving mental and physical health status. ${ }^{1-3}$ The use of DSs is prevalent among US civilians and Armed Forces personnel, with approximately $50 \%$ and $60 \%$, respectively, being regular consumers of DSs. ${ }^{1-3}$ Both civilians and military personnel report a high level of confidence, $82 \%$ and $71 \%$ respectively, that DSs are safe and

From the *US Army Research Institute of Environmental Medicine, Natick, MA; and †Oak Ridge Institute for Science and Education, Belcamp, MD. Received February 5, 2014; accepted after revision May 14, 2014.

This work was supported by the US Army Research and Material Command and the Department of Defense Center Alliance for Dietary Supplement Research.

Reprints: Harris R. Lieberman, PhD, Military Nutrition Division, US Army Research Institute of Environmental Medicine, Natick, MA 01760 (e-mail: harris.r.lieberman.civ@mail.mil).

This is an open-access article distributed under the terms of the Creative Commons Attribution-NonCommercial-NoDerivatives 3.0 License, where it is permissible to download and share the work provided it is properly cited. The work cannot be changed in any way or used commercially.

Copyright (C) 2014 by Lippincott Williams \& Wilkins

ISSN: 0271-0749

DOI: 10.1097/JCP.0000000000000193 effective. ${ }^{4,5}$ Military personnel use DSs for a variety of reasons including compensation for presumed inadequacy of their diet, prevention of illness, improving mental health, increasing energy levels, and overcoming feelings of psychological stress. ${ }^{3,6}$ Similarly, civilians report the use of DSs to reduce physical and mental stress, anxiety, and fatigue, as well as to increase energy levels. ${ }^{2,7-10}$ Despite these reports, little research has examined the relationship of DS use to psychological status in healthy populations.

Clinical trials and epidemiological studies have observed improved mood and psychological status with use of multivitamin and mineral (MVM) DSs ${ }^{11-15}$; however, these relationships are typically observed in special populations such as elderly individuals who often display suboptimal micronutrient status. ${ }^{15}$ There is minimal evidence for a positive effect of MVM on mood in healthy nonelderly adults. Benton et $\mathrm{al}^{14}$ have reported that 12 months of supplementation in young, healthy adults with a high-dose multivitamin improves mood, although effects were observed only in female participants. More recently, Kennedy et a ${ }^{12}$ reported improvements in vigor after 4 weeks of MVM supplementation; however, the observed effects were moderate and should be interpreted with caution, given the small cohort studied. Thus, it is not known whether MVM use is associated with mood in healthy individuals, and to the best of our knowledge, effects of other DS classes on mood status have not been evaluated in large population samples.

Studies investigating effects of DSs may be influenced by multiple lifestyle factors of participants including health-related behaviors. ${ }^{16,17}$ Self-efficacy, an individual's belief in the ability to successfully execute behaviors required to produce a desired outcome, can significantly influence health behavior. ${ }^{16-19}$ The use of DSs has been shown to be highest among persons who rate their health as excellent or very good. ${ }^{16,17}$ In addition, positive mood states have been associated with an individual's perception of their health behaviors. ${ }^{18,19}$ Given the lack of knowledge regarding the effects of DS use on mood and the possible confounding effect of an association between mood, health behavior, and DS use on studies of DSs, we examined the association of mood state and health behavior self-efficacy with multiple classes of DSs.

\section{METHODS}

\section{Ethics Statement}

This study was approved by the Human Use Review Committee at the US Army Research Institute of Environmental Medicine. No incentives were offered to participants for completion of the survey. Participants completed the survey after an explanation that all information obtained would remain confidential and that participation was voluntary (no identifying data were collected) and that they were free to withdraw from the study at anytime. Completion and return of the survey served as each participant's written informed consent. Investigators adhered to US Army Regulation 70-25 and US Army Medical Research and Materiel Command Regulation $70-25$ on the use of volunteers in research. ${ }^{20}$ 


\section{Participants}

The final sample consisted of 5536 military and Coast Guard personnel. In 2006-2007, a total of 990 US Army Soldiers completed the survey, and in 2010-2011, 1207 Army, 1787 Air Force, 1059 Coast Guard, and 483 deployed personnel completed the survey. All analyses were performed in the Fall of 2012. The sample from 2006-2007 was collected at 11 Army bases: 9 US installations and 2 overseas sites. For the 2010-2011 survey, 12 Army (10 US installations and 2 overseas sites), 8 Air Force (7 US installations and 1 overseas site), and 13 Coast Guard bases (all US installations) participated in data collection. All active duty US Army, Air Force, and Coast Guard personnel were eligible to complete the survey (504,422 Army personnel as of January 1, 2007; 533,107 Army; 344,683 Air Force; and 41,594 Coast Guard personnel as of November 30, 2011). Individuals who were on temporary or transitional status, including individuals absent without leave, incarcerated, or moving between permanent duty stations, were excluded. We did not survey individuals enrolled in Basic Combat Training or Advanced Individual training because they are prohibited from consuming DSs. The estimated response rate of individuals whom we attempted to recruit for the study was $65 \%$. Based on data available regarding the composition of the military services we studied, it appears our sample was generally representative of each service with regard to key demographic factors such as sex, age, and rank. Users and nonusers of DSs were included in the sample. Survey sites were chosen based on the distribution of the Army, Air Force, and Coast Guard populations and the availability of health care professionals to administer the survey. Health care professionals recruited units at their respective bases that were reflective of the installation's population.

\section{Survey}

Prior to administering the survey, participants were briefed regarding its contents, and appropriate procedures for completing all questions were provided. The survey consisted of 43 questions and assessed type of DSs used and frequency of use; self-reported measures of health behavior including overall general health, eating habits, and fitness level; and current mood state using the Quick Mood Scale. ${ }^{21}$

Ninety-two individual supplements were listed in the survey including 55 general supplements such as multivitamins, individual vitamins and minerals, combination antioxidants, and 37 specifically named products. Brand name DSs chosen for inclusion were based on then-current patterns of DS purchases at the Army Air Force Exchange System and General Nutrition Center stores located on or near military installations. Prior to data analysis, individual supplement and supplement types were grouped into the following categories based on the definitions provided in Table 1: MVM, individual vitamins and minerals (IVM), protein/amino acid supplements (PS), combination products (C), herbal supplements $(\mathrm{H})$, purported steroid analogs $(\mathrm{S})$, and other $(\mathrm{O})$. A standardized taxonomy similar to those used in national surveys, such as the National Health and Nutrition and Examination Survey, was used to categorize DSs. ${ }^{1}$ Survey questions assessing participants" health behavior self-efficacy were as follows: "How do you consider your general health?", "How do you consider your overall eating habits?", and "How do you consider your overall fitness level?" For each question, participants selected between 4-response options: "excellent," "good," "fair," or "poor." After preliminary data analyses were conducted, response options were collapsed into the categories of "excellent/good" and "fair/poor" because of low cell counts in some response options.

Mood state was assessed using the Quick Mood Scale, which assesses states of wakeful-drowsiness, relaxed-anxious, cheerful-
TABLE 1. Dietary Supplement Categories as Defined in Dietary Supplement Intake Survey of US Active Duty Personnel

\begin{tabular}{ll}
\hline Category & \multicolumn{1}{c}{ Definition } \\
\hline DS & Any DSs as defined by the DSHEA legislation \\
Multivitamins & $\begin{array}{c}\text { DSs containing } \geq 2 \text { vitamins and no additional } \\
\text { supplement ingredients }\end{array}$ \\
Multiminerals & $\begin{array}{c}\text { DSs containing } \geq 2 \text { minerals and no additional } \\
\text { supplement ingredients } \\
\text { Amino acid mixtures, protein powders, and } \\
\text { PS }\end{array}$ \\
& similar products where the intention is to provide \\
& a single or complex protein source \\
IVM & DSs that were single nutrient ingredient \\
& supplements, such as calcium or vitamin D \\
C & DSs with mixtures of ingredients from any of the \\
& above categories; included $\geq 2$ categories and \\
& multiple ingredients \\
H & DSs that included $\geq 1$ herbal ingredients with no \\
& nutrients or other supplement ingredients; also \\
& includes plant-derived ingredients \\
S & Steroidal hormones or herbal substitutes for \\
& hormones that were marketed as DSs and \\
& included the Supplement Facts panel on the label
\end{tabular}

DSHEA indicates Dietary Supplement Health and Education Act of 1994 (21 U.S.C. $\$ 401$ (q)(5)).

depressed, friendly-aggression, clearheaded-confused, and well coordinated-clumsy. ${ }^{21}$ Participants rate each individual mood descriptor according to one of the following: not at all, a little, moderately, very, or extremely based on how they are feeling at the present moment. Scores for the 12 scales are combined into the 6 states by taking the "positive" rating (eg, wakeful, relaxed, cheerful, friendly, clearheaded, well coordinated) of each dimension and scoring the response between 0 and 4, then subtracting the respective "negative" (eg, drowsy, anxious, depressed, aggression, confused, clumsy) score and then adding 4 to give a positive result between 0 and 8 . The 6 categories of the Quick Mood Scale are highly correlated with the corresponding subscales of the profile of mood states, a widely used, longer-length mood questionnaire. ${ }^{21}$

\section{Data Analysis}

Completed surveys were scanned using ScanTools Plus with ScanFlex (version 6.301; Scantron Corporation, Eagan, Minn), and data were imported into SPSS (version 20.0; SPSS Inc, Chicago, IL) for data analysis. A 1-way analysis of covariance (ANCOVA) was conducted to determine associations between DSs and mood, after controlling for age. Data were not weighted for overall composition of each service as we were interested in service-independent relationships. However, additional covariates, including time spent performing aerobic exercise, participation in strength training, self-reported measures of behavioral health, and other demographic factors such as body mass index, marital status, sex, rank, and education, were explored for inclusion as covariates when examining associations with mood state; however, no significant associations between these covariates and outcome measures of interest were observed; thus, these potential confounders were not included as covariates in final models. Levels of significance were adjusted for multiple comparisons using the Bonferroni correction procedure. Results of ANCOVA analyses are presented as adjusted means and SEs. Logistic regression was used to examine the likelihood of DS use as a function of self-reported behavioral health adjusted for age. Logistic regression analyses are presented as odds ratios (ORs) and 95\% confidence intervals (CIs). 


\section{RESULTS}

Demographic characteristics of participants are presented in Table 2. Sixty-nine percent $(n=3828)$ of participants reported using a DSs 1 or more time per week for the 6 months prior to the survey. Forty-three percent $(n=2365)$ of participants consumed an MVM, 30\% $(\mathrm{n}=1648)$ a protein supplement, $28 \%$ $(\mathrm{n}=1194)$ an individual vitamin or mineral, $22 \%(\mathrm{n}=1232) \mathrm{com}-$ bination products, $20 \%(\mathrm{n}=1089)$ consumed a supplement classified as "other," $9 \%(n=495)$ a herbal supplement, and $2 \%(n=91)$ a supplement classified as a steroid analog at least once a week.

\section{Relationship Between Mood and DS Use}

Differences in mood states between users and nonusers of DSs and classes of DSs are presented in Table 3. Analysis of covariance revealed no significant differences between users and nonusers of DSs for all mood states when all classes of DSs were combined. When examining individual classes of DSs, users of MVM and PS demonstrated significant differences in mood states compared with nonusers. Users of MVM reported feeling significantly more awake (wide awake-drowsy; $\mathrm{F}=18.134, P<0.001$ ), relaxed (relaxed-anxious; $\mathrm{F}=9.780, P<0.01$ ), cheerful (cheerfuldepressed; $\mathrm{F}=12.208, P<0.001$ ), friendly (friendly-aggressive; $\mathrm{F}=4.992, P=0.03$ ), clearheaded (clearheaded-confused; $\mathrm{F}=$ 29.421, $P<0.001$ ), and well coordinated (well coordinatedclumsy; $\mathrm{F}=23.849, P<0.001$ ). Similarly, individuals consuming PS also reported they were more awake (wide awake-drowsy; $\mathrm{F}=24.302, P<0.000$ ), relaxed (relaxed-anxious; $\mathrm{F}=11.780$, $P<0.001$ ), cheerful (cheerful-depressed F $=7.413, P<0.01$ ), aggressive (friendly-aggressive; $\mathrm{F}=5.484, P=0.02$ ), clearheaded (clearheaded-confused; $\mathrm{F}=32.004, P<0.001$ ), and well coordinated (well coordinated-clumsy; $\mathrm{F}=63.226, P<0.001$ ).

Users of $\mathrm{C}$ reported feeling more friendly (friendly-aggressive; $\mathrm{F}=4.967, P=0.03$ ) and well coordinated (well coordinatedclumsy; $\mathrm{F}=20.783, P<0.001)$; $\mathrm{H}$ users reported feeling more friendly on the friendly-aggressive scale $(\mathrm{F}=7.815, P<0.01)$; users of $\mathrm{S}$ reported feeling less friendly and more aggressive $(\mathrm{F}=$ 16.504, $P<0.001)$; and users of $\mathrm{O}$ reported feeling significantly more cheerful (cheerful-depressed; $\mathrm{F}=6.915, P<0.01$ ) and well coordinated (well coordinated-clumsy; $\mathrm{F}=5.260, P=0.02$ ). In general, overall positive mood states were associated with specific

TABLE 2. Demographic Characteristics of Dietary Supplement Users and Nonusers

\begin{tabular}{|c|c|c|}
\hline & User & Nonuser \\
\hline \multicolumn{3}{|l|}{ Age, y } \\
\hline Female & $28.6 \pm 0.2 *$ & $26.8 \pm 0.4$ \\
\hline Male & $28.8 \pm 0.2 *$ & $27.8 \pm 0.3$ \\
\hline \multicolumn{3}{|l|}{ Height, in } \\
\hline Female & $66.5 \pm 0.3$ & $66.1 \pm 0.3$ \\
\hline Male & $69.6 \pm 0.1$ & $69.4 \pm 0.1$ \\
\hline \multicolumn{3}{|l|}{ Weight, lb } \\
\hline Female & $162.1 \pm 1.4^{*}$ & $154.1 \pm 2.74$ \\
\hline Male & $182.0 \pm 0.6^{\dagger}$ & $179.7 \pm 0.8$ \\
\hline \multicolumn{3}{|c|}{ Body mass index, $\mathrm{kg} / \mathrm{m}^{2}$} \\
\hline Female & $25.7 \pm 0.1$ & $25.4 \pm 0.3$ \\
\hline Male & $26.5 \pm 0.1 *$ & $25.4 \pm 0.3$ \\
\hline \multicolumn{3}{|c|}{$\begin{array}{l}\text { Results of a 1-way analysis of variance revealed significant difference } \\
\text { between demographic characteristics of males and female participants. } \\
\quad{ }^{*} P<0.01 \text {. } \\
{ }^{\dagger} P<0.05 \text {. }\end{array}$} \\
\hline
\end{tabular}

classes of DSs, with the occasional exception for the mood state of friendly-aggressive.

\section{Relationship Between Self-Reported Measures of Behavioral Health, Mood, and DS Use}

Mood states as a function of self-reported measures of behavioral health are presented in Table 4. Respondents self-reporting their overall general health as being "excellent/good" were significantly more wide awake (wide awake-drowsy; $\mathrm{F}=25.021$, $P<0.001$ ), relaxed (relaxed-anxious; $\mathrm{F}=33.280, P<0.001$ ), cheerful (cheerful-depressed; $\mathrm{F}=45.906, P<0.001$ ), friendly (friendly-aggressive; $\mathrm{F}=20.445, P<0.001$ ), clearheaded (clearheaded-confused; $\mathrm{F}=25.116, P<0.001$ ), and well coordinated (well coordinated-clumsy; F $=26.071, P<0.001$ ). Participants rating their eating habits as "excellent/good" reported feeling significantly more wide awake (wide awake-drowsy; $\mathrm{F}=31.015, P<0.001$ ), relaxed (relaxed-anxious; $\mathrm{F}=20.356$, $P<0.001$ ), cheerful (cheerful-depressed; $\mathrm{F}=41.714, P<0.001$ ), friendly (friendly-aggressive; $\mathrm{F}=9.949, P<0.001$ ), clearheaded (clearheaded-confused; $\mathrm{F}=25.254, P<0.001$ ), and well coordinated (well coordinated-clumsy; $\mathrm{F}=29.111, P<0.001$ ). Those reporting their fitness level as being "excellent/good" were also significantly more wide awake (wide awake-drowsy; $\mathrm{F}=23.467, P<0.001$ ), relaxed (relaxed-anxious; $\mathrm{F}=24.170$, $P<0.001$ ), cheerful (cheerful-depressed; $\mathrm{F}=40.068, P<0.001$ ), friendly (friendly-aggressive; $\mathrm{F}=6.727, P<0.001$ ), clearheaded (clearheaded-confused; $\mathrm{F}=12.864, P<0.001$ ), and well coordinated (well coordinated-clumsy; $\mathrm{F}=22.536, P<0.001$ ).

Relationships of all DS classes to health-related behaviors are presented in Table 5. In general, when users of all classes of DSs were combined, DS users were more likely to rate their eating habits (OR, 1.41; CI, 1.25-1.59) or fitness level (OR, 1.34; CI, 1.17-1.53) as being "excellent/good" compared with nonusers. Users of MVM (OR, 1.29; CI, 1.08-1.53), PS (OR, 1.58; CI, 1.29-1.93), C products (OR, 1.25; CI, 1.01-1.54), and S (OR, 2.73 ; CI, 1.00-7.47) were more likely to report their overall general health as "excellent/good." Participants using an MVM (OR, 1.41; CI, 1.26-1.59), PS (OR, 1.54; CI, 1.36-1.76), IVM (OR, 1.26; CI, 1.10-1.45), C (OR, 1.33; CI, 1.15-1.53), or DSs classified as $\mathrm{O}(\mathrm{OR}, 1.39$; $\mathrm{CI}, 1.20-1.61)$ were more likely to rate their eating habits as "excellent/good." Similarly, users of MVM (OR, 1.35; CI, 1.19-1.54), PS (OR, 2.02; CI, 1.73-2.36), C (OR, 1.70; CI, 1.44-2.02), or O (OR, 1.37; CI, 1.16-1.62) were more likely to report a fitness level of "excellent/good."

\section{DISCUSSION}

In a large sample of military and Coast Guard personnel, we observed numerous associations between multiple mood states and use of specific DSs. We found that positive changes in 6 fundamental dimensions of mood, wakefulness, feeling more relaxed, cheerful, friendly, clearheaded, and well coordinated, are associated with use of both MVM and PS. Users of MVM also reported feeling friendlier, but users of PS reported feeling more aggressive. Like previous reports in athletes and body builders, we also observed that users of S report feeling more aggressive. ${ }^{2,23}$ Specific classes of DSs were also more likely to be used among personnel who consider their health, fitness, and eating habits to be excellent or good and least likely among those who report it is fair or poor, findings that are consistent with reports in the civilian population. ${ }^{17-19}$ Furthermore, in agreement with the civilian literature, we also report a higher level of health behavior selfefficacy in Armed Forces personnel who report a more positive mood state. ${ }^{17}$ 
TABLE 3. Relationship Between Mood and Dietary Supplement Intake*

\begin{tabular}{|c|c|c|c|c|c|c|c|c|}
\hline Quick Mood Score & Any DSs & MVM & PS & IVM & $\mathbf{C}$ & $\mathbf{H}$ & $\mathbf{S}$ & Other \\
\hline Nonusers, $\mathrm{n}$ & 2467 & 3171 & 3888 & 4342 & 4304 & 5041 & 5445 & 4447 \\
\hline Users, $\mathrm{n}$ & 3069 & 2365 & 1648 & 1194 & 1232 & 495 & 91 & 1089 \\
\hline \multicolumn{9}{|c|}{ Wide awake and drowsy } \\
\hline Nonuser & $5.16 \pm 0.04$ & $5.08 \pm 0.03$ & $5.08 \pm 0.03$ & $5.14 \pm 0.03$ & $5.13 \pm 0.03$ & $5.16 \pm 0.03$ & $5.15 \pm 0.03$ & $5.14 \pm 0.03$ \\
\hline User & $5.16 \pm 0.03$ & $5.29 \pm 0.04^{\dagger}$ & $5.35 \pm 0.05^{\dagger}$ & $5.24 \pm 0.06$ & $5.25 \pm 0.05$ & $5.20 \pm 0.09$ & $5.52 \pm 0.20$ & $5.25 \pm 0.06$ \\
\hline \multicolumn{9}{|l|}{ Relaxed and anxious } \\
\hline Nonuser & $5.11 \pm 0.03$ & $5.03 \pm 0.03$ & $5.04 \pm 0.03$ & $5.11 \pm 0.03$ & $5.08 \pm 0.03$ & $5.10 \pm 0.02$ & $5.09 \pm 0.02$ & $5.07 \pm 0.03$ \\
\hline User & $5.07 \pm 0.03$ & $5.17 \pm 0.04^{\ddagger}$ & $5.21 \pm 0.04^{\dagger}$ & $5.02 \pm 0.05$ & $5.12 \pm 0.05$ & $4.97 \pm 0.08$ & $4.98 \pm 0.18$ & $5.18 \pm 0.05$ \\
\hline \multicolumn{9}{|c|}{ Cheerful and depressed } \\
\hline Nonuser & $5.42 \pm 0.04$ & $5.33 \pm 0.03$ & $5.36 \pm 0.03$ & $5.39 \pm 0.03$ & $5.39 \pm 0.03$ & $5.41 \pm 0.02$ & $5.41 \pm 0.02$ & $5.37 \pm 0.03$ \\
\hline User & $5.39 \pm 0.03$ & $5.50 \pm 0.04^{\dagger}$ & $5.50 \pm 0.04^{\ddagger}$ & $5.45 \pm 0.05$ & $5.46 \pm 0.05$ & $5.39 \pm 0.08$ & $5.31 \pm 0.18$ & $5.53 \pm 0.05^{*}$ \\
\hline \multicolumn{9}{|c|}{ Friendly and aggressive } \\
\hline Nonuser & $5.57 \pm 0.04$ & $5.49 \pm 0.03$ & $5.57 \pm 0.03$ & $5.53 \pm 0.03$ & $5.56 \pm 0.03$ & $5.55 \pm 0.03$ & $5.55 \pm 0.02$ & $5.53 \pm 0.03$ \\
\hline User & $5.50 \pm 0.03$ & $5.59 \pm 0.04^{\S}$ & $5.45 \pm 0.04^{\S}$ & $5.53 \pm 0.05$ & $5.43 \pm 0.05^{\S}$ & $5.32 \pm 0.08^{\ddagger}$ & $4.79 \pm 0.18^{\dagger}$ & $5.53 \pm 0.05$ \\
\hline \multicolumn{9}{|c|}{ Clearheaded and confused } \\
\hline Nonuser & $5.92 \pm 0.03$ & $5.81 \pm 0.03$ & $5.83 \pm 0.03$ & $5.92 \pm 0.03$ & $5.90 \pm 0.03$ & $5.92 \pm 0.02$ & $5.91 \pm 0.02$ & $5.88 \pm 0.03$ \\
\hline User & $5.91 \pm 0.03$ & $6.06 \pm 0.04^{\dagger}$ & $6.12 \pm 0.04^{\dagger}$ & $5.91 \pm 0.05$ & $5.98 \pm 0.05$ & $5.84 \pm 0.08$ & $6.09 \pm 0.18$ & $6.06 \pm 0.05$ \\
\hline \multicolumn{9}{|c|}{ Well coordinated and clumsy } \\
\hline Nonuser & $5.93 \pm 0.03$ & $5.84 \pm 0.03$ & $5.82 \pm 0.03$ & $5.93 \pm 0.03$ & $5.88 \pm 0.03$ & $5.94 \pm 0.02$ & $5.93 \pm 0.02$ & $5.91 \pm 0.03$ \\
\hline User & $5.95 \pm 0.03$ & $6.07 \pm 0.03^{\dagger}$ & $6.21 \pm 0.04^{\dagger}$ & $5.96 \pm 0.05$ & $6.13 \pm 0.05^{\dagger}$ & $5.89 \pm 0.08^{\dagger}$ & $6.17 \pm 0.18$ & $6.04 \pm 0.05^{\S}$ \\
\hline
\end{tabular}

Scores for the 12 scales are combined into the 6 states by taking the "positive" (eg, wide awake) of each dimension and scoring the response between 0 and 4, then subtracting the "negative" (eg, drowsy) score and then finally adding 4 to give a positive result between 0 and 8 .

*All values are adjusted means and SEs. Analysis of covariance was used to determine significant differences in mood state between users and nonusers of DSs.

$$
\begin{aligned}
& \dagger P<0.001 . \\
& { }^{\sharp} P<0.01 . \\
& { }^{\S} P<0.05 .
\end{aligned}
$$

Our finding with respect to mood and MVM use is largely in agreement with results of clinical trials and a recent meta-analysis performed by Long and Benton, ${ }^{12-15}$ who observed an association between MVM supplementation and various mood states in adults. However, unlike these studies, we found that MVM use was associated with a beneficial effect on all dimensions of mood that were assessed, including depression and hostility. The reported differences may be attributable to the greater number of volunteers we studied $(\mathrm{N}=5536)$ which is a considerably larger population than what has previously been used in clinical trials $(<300)$ or the pooled sample $(N=1292)$ for the meta-analysis performed by Long and Benton, ${ }^{12-15}$ thus providing greater statistical power to detect statistically significant relationships between mood and MVM use. ${ }^{12-15}$

In addition to detecting associations between mood and

\begin{tabular}{|c|c|c|c|c|c|c|}
\hline & $\begin{array}{l}\text { Wide Awake } \\
\text { and Drowsy }\end{array}$ & $\begin{array}{c}\text { Relaxed and } \\
\text { Anxious }\end{array}$ & $\begin{array}{c}\text { Cheerful and } \\
\text { Depressed }\end{array}$ & $\begin{array}{l}\text { Friendly and } \\
\text { Aggressive }\end{array}$ & $\begin{array}{c}\text { Clearheaded and } \\
\text { Confused }\end{array}$ & $\begin{array}{c}\text { Well Coordinated } \\
\text { and Clumsy }\end{array}$ \\
\hline \multicolumn{7}{|l|}{ General health } \\
\hline Excellent/good $(n=3947)$ & $5.22 \pm 0.03 *$ & $5.16 \pm 0.02 *$ & $5.48 \pm 0.02 *$ & $5.58 \pm 0.03 *$ & $5.97 \pm 0.02 *$ & $6.00 \pm 0.02 *$ \\
\hline Fair/poor $(\mathrm{n}=357)$ & $4.66 \pm 0.08$ & $4.57 \pm 0.07$ & $4.79 \pm 0.07$ & $5.13 \pm 0.07$ & $5.46 \pm 0.07$ & $5.49 \pm 0.07$ \\
\hline \multicolumn{7}{|l|}{ Overall eating habits } \\
\hline Excellent/good $(n=3109)$ & $5.30 \pm 0.03 *$ & $5.19 \pm 0.03^{*}$ & $5.55 \pm 0.03 *$ & $5.60 \pm 0.03 *$ & $6.03 \pm 0.02 *$ & $6.06 \pm 0.03 *$ \\
\hline Fair/poor $(\mathrm{n}=1195)$ & $4.87 \pm 0.05$ & $4.88 \pm 0.04$ & $5.10 \pm 0.04$ & $5.40 \pm 0.04$ & $5.68 \pm 0.04$ & $5.69 \pm 0.04$ \\
\hline \multicolumn{7}{|l|}{ Overall fitness level } \\
\hline Excellent/good $(\mathrm{n}=3441)$ & $5.25 \pm 0.03^{*}$ & $5.18 \pm 0.03 *$ & $5.52 \pm 0.03 *$ & $5.58 \pm 0.03 *$ & $5.98 \pm 0.03 *$ & $6.02 \pm 0.05^{*}$ \\
\hline Fair/poor $(\mathrm{n}=862)$ & $4.85 \pm 0.05$ & $4.80 \pm 0.05$ & $5.02 \pm 0.05$ & $5.38 \pm 0.05$ & $5.71 \pm 0.05$ & $5.66 \pm 0.05$ \\
\hline
\end{tabular}
MVM use, we also observed that PS use was associated with

TABLE 4. Relationship Between Mood and Self-Reported Measures of Behavioral Health

All values are adjusted means and SEs. Analysis of covariance was used to determine significant differences in mood state between users and nonusers of DSs. Scores for the 12 scales are combined into the 6 states by taking the "positive" (eg, wide awake) of each dimension and scoring the response between 0 and 4 , then subtracting the "negative" (eg, drowsy) score and then finally adding 4 to give a positive result between 0 and 8 .

$* P<0.001$. 
TABLE 5. Association Between DS Use and Self-Reported Behavioral Health

\begin{tabular}{|c|c|c|c|c|c|c|c|c|}
\hline & Any DSs & MVM & PS & IVM & $\mathbf{C}$ & $\mathbf{H}$ & $\mathbf{S}$ & Other \\
\hline \multicolumn{9}{|c|}{ Overall general health } \\
\hline \multirow[t]{3}{*}{ Excellent/good } & 1.18 & $1.29 *$ & $1.58^{\dagger}$ & 1.08 & $1.25^{*}$ & 0.97 & $2.73^{*}$ & 1.19 \\
\hline & $(0.987-1.41)$ & $(1.08-1.53)$ & $(1.29-1.93)$ & $(0.87-1.33)$ & $(1.01-1.54)$ & $(0.72-1.30)$ & $(1.00-7.47)$ & $(0.95-1.48)$ \\
\hline & $\mathrm{n}=4910$ & $\mathrm{n}=2133$ & $\mathrm{n}=1512$ & $\mathrm{n}=1067$ & $\mathrm{n}=1112$ & $\mathrm{n}=438$ & $\mathrm{n}=70$ & $\mathrm{n}=981$ \\
\hline \multirow[t]{2}{*}{ Fair/poor } & 1.00 & 1.00 & 1.00 & 1.00 & 1.00 & 1.00 & 1.00 & 1.00 \\
\hline & $\mathrm{n}=610$ & $\mathrm{n}=228$ & $\mathrm{n}=134$ & $\mathrm{n}=125$ & $\mathrm{n}=116$ & $\mathrm{n}=56$ & $\mathrm{n}=2$ & $\mathrm{n}=106$ \\
\hline \multicolumn{9}{|c|}{ Overall eating habits } \\
\hline \multirow[t]{3}{*}{ Excellent/good } & 1.41 & $1.41^{\dagger}$ & $1.54^{\dagger}$ & $1.26^{\dagger}$ & $1.33^{\dagger}$ & 1.15 & $1.79 *$ & $1.39^{\dagger}$ \\
\hline & $(1.25-1.59)$ & $(1.26-1.59)$ & $(1.36-1.76)$ & $(1.10-1.45)$ & $(1.15-1.53)$ & $(0.93-1.41)$ & $(1.08-2.98)$ & $(1.20-1.61)$ \\
\hline & $\mathrm{n}=3759$ & $\mathrm{n}=1708$ & $\mathrm{n}=1226$ & $\mathrm{n}=858$ & $\mathrm{n}=895$ & $\mathrm{n}=355$ & $\mathrm{n}=72$ & $\mathrm{n}=800$ \\
\hline \multirow[t]{2}{*}{ Fair/poor } & 1.00 & 1.00 & 1.00 & 1.00 & 1.00 & 1.00 & 1.00 & 1.00 \\
\hline & $\mathrm{n}=1760$ & $\mathrm{n}=653$ & $\mathrm{n}=420$ & $\mathrm{n}=334$ & $\mathrm{n}=335$ & $\mathrm{n}=139$ & $\mathrm{n}=19$ & $\mathrm{n}=287$ \\
\hline \multicolumn{9}{|c|}{ Overall fitness level } \\
\hline \multirow[t]{3}{*}{ Excellent/good } & 1.34 & $1.35^{\dagger}$ & $2.02^{\dagger}$ & 1.02 & $1.70^{\dagger}$ & 1.24 & 1.78 & $1.37^{\star}$ \\
\hline & $(1.17-1.53)$ & $(1.19-1.54)$ & $(1.73-2.36)$ & $(0.87-1.18)$ & $(1.44-2.02)$ & $(0.98-1.56)$ & $(0.98-3.20)$ & $(1.16-1.62)$ \\
\hline & $\mathrm{n}=4266$ & $\mathrm{n}=1896$ & $\mathrm{n}=1401$ & $\mathrm{n}=924$ & $\mathrm{n}=1030$ & $\mathrm{n}=398$ & $\mathrm{n}=78$ & $\mathrm{n}=887$ \\
\hline \multirow[t]{2}{*}{ Fair/poor } & 1.00 & 1.00 & 1.00 & 1.00 & 1.00 & 1.00 & 1.00 & 1.00 \\
\hline & $\mathrm{n}=1252$ & $\mathrm{n}=466$ & $\mathrm{n}=244$ & $\mathrm{n}=268$ & $\mathrm{n}=197$ & $\mathrm{n}=96$ & $\mathrm{n}=13$ & $\mathrm{n}=201$ \\
\hline
\end{tabular}

All values are ORs, $95 \%$ CIs in parentheses. Significant values are presented on the basis of logistic regression modeling.

$* P<0.05$.

${ }^{\dagger} P<0.001$.

${ }^{\sharp} P<0.01$.

positive mood in all the mood states we examined except aggression. An increased level of aggression by users of PS is in agreement with previous studies reporting increased anger in healthy individuals consuming a high-protein, low-carbohydrate diet. ${ }^{22}$ Although there are numerous reports that supplementation with various combinations of vitamins and minerals may be associated with changes in mood, given the lack of consistent effects on specific mood domains and that PS and MVM have no shared biological mechanism of action, we interpret our findings as suggesting that the effects of MVM and PS use on mood are nonspecific and noncausal in nature. However, the differences reported between the present analyses and results of other studies may also reflect the difference in study methodology, questionnaires used to assess mood, or population differences. Long-term, large clinical trials are necessary to elucidate the effects of MVM and PS on mood and other aspects of psychological status. Examining effects of PS on mood is especially warranted given the increasing popularity and concomitant use of PS and high-protein diets among civilians, athletes, and Armed Forces personnel..$^{23-26}$ Such studies should be conducted using the most rigorous method used in clinical trials of potentially psychoactive compounds.

The largest relationship observed in the present study was significantly greater feelings of aggression in study participants reporting use of S (ANCOVA, $P<0.001$ ). Athletes and bodybuilders using steroids have been reported to exhibit behavioral changes induced by steroids, in particular increases in aggression and violence. ${ }^{27,28}$ Parrott et $\mathrm{al}^{27,28}$ reported increased feelings of alertness, irritability, anxiety, suspiciousness, and negativism in steroid users; however, there was no evidence of similar changes in the Armed Forces population we assessed. Dietary supplements sold as S contain a wide variety of ingredients, such as $17 \alpha-$ methylepithiostanol, desoxymethyl-testosterone, and androsta1,4,6-triene-3,17-dione, but there is little evidence any of these compounds are biologically active and affect brain function. Thus, the effect of $\mathrm{S}$ we report may be the consequence of reverse causation; individuals who feel more aggressive may choose to use these types of DSs. Regardless, given that steroids and their derivatives could produce undesirable behavioral or physiological effects, their potential adverse effects in Armed Forces personnel, as well as in civilians, should be examined. ${ }^{29-31}$ Additional research is necessary to determine if steroid analog DSs are biologically active and if they provide an effective dose of their active ingredient(s) when administered in DSs.

Users of MVM, PS, and C were more likely to consider their general health as excellent or good, but not users of IVM, H, or O. Users of $\mathrm{H}$ reported a lower level of health self-efficacy as it related to eating habits or fitness, and similarly, users of IVM and $\mathrm{S}$ were less likely to perceive their overall fitness level as excellent or good. Differences in health-related behaviors between DS users and nonusers have not typically been examined. Recent research has found use of DSs may inhibit healthy behaviors, resulting in less exercise, unhealthy food choices and the pursuit of other hedonic activities, a process termed psychological licensing. ${ }^{32}$ Consistent with some reports in the civilian population, ${ }^{16,18}$ our findings suggest that use of particular classes of DSs, such as IVM, H, or S, may encourage supplement users to engage in unhealthy behaviors, and further investigation may be warranted.

In civilians, mood has been reported to influence healthrelevant attitudes. ${ }^{18,32,33}$ Like the civilian population, Armed Forces personnel with a more negative mood state were less likely to view their general health, fitness, and eating habits as excellent or good. Bandura ${ }^{18,32,33}$ noted that a more negative mood state can adversely influence self-motivating processes that drive participation in health-promoting behaviors such as exercise and healthy eating. Our findings suggest that mood also influences perceptions of health within the military and Coast Guard populations and thus may influence DS use.

Previous studies investigating differences between DS users and nonusers have observed demographic, lifestyle, dietary, and health characteristics can influence DS use. ${ }^{16}$ Given the multiple 
nonspecific effects of DS use on mood identified in the present study, we suggest that mood influences DS use and may act as a confounding factor in studies of DSs. Because DS use and high levels of health self-efficacy are associated with a more positive mood state, differences in mood may need to be assessed and adjusted for in clinical and observational studies evaluating the impact of DS use.

\section{LIMITATIONS AND STRENGTHS}

This study observed robust associations between DS use, mood, and health behavior, but limitations of the study should be acknowledged. Evidence for a relationship between mood, health behavior, and DS use would be stronger if mood and health behaviors were assessed for a longer period. Also, whereas age was used as a covariate to control for confounding factors, other unidentified factors not assessed in this study may have influenced the results and cannot be accounted. In addition, because participation was voluntary, we may have selectively surveyed military and Coast Guard personnel who are more willing to complete surveys or have strong beliefs regarding DS use. Finally, in the present study, we were unable to test DS used by participants for potential contamination with steroids or other mood-altering agents, which may have influenced the results on mood we observed. It has been reported that some DSs, especially S, may be "spiked" with potent contaminants. Despite these limitations, multiple strengths of the present study, including the large and diverse sample, use of multivariate analyses, and data sampling procedures, suggest that findings from this study can be generalized to the larger Armed Forces population. Similar studies should be conducted in the civilian population.

\section{CONCLUSIONS}

As no mechanisms can realistically explain the diverse effects of different types of DSs on diverse moods, we suggest this association is not causal, and DS intake per se does not alter mood. Studies of DSs should consider whether mood differences in users versus nonusers could be a confounding factor. In general, positive mood states are associated with DS use and a greater level of health self-efficacy in military and Coast Guard personnel. Based on the present study and recent evidence from others, our findings suggest the use of certain DS classes may result in a perceived invulnerability to poor mental and physical health and therefore adversely affect health.

\section{AUTHOR DISCLOSURE INFORMATION}

The authors have no conflicts of interest to declare.

\section{REFERENCES}

1. Lieberman H, Stavinoha T, McGraw S, et al. Use of dietary supplements among active-duty US Army soldiers. Am J Clin Nutr. 2010;92:985-995.

2. Gahche J, Bailey R, Burt V, et al. Dietary supplement use among U.S. adults has increased since NHANES III (1988-1994). NCHS Data Brief. 2011;(61):1-8.

3. DoD. Survey of Health Related Behaviors Among Active Duty Military Personnel. Washington, DC: Department of Defense; 2005.

4. Carvey C, Farina E, Lieberman H. Confidence in the efficacy and safety of dietary supplements among United States active duty army personnel. BMC Complement Altern Med. 2012;12:1-12.

5. Council for Responsible Nutrition. Supplement Usage, Consumer Confidence Remains Steady. Washington, DC: Council for Responsible Nutrition; 2010 Available at: http://www.crnusa.org/prpdfs/
CRNPR10ConsumerSurveyUsage+Confidence.pdf. Accessed January 14, 2014

6. IOM. Use of Dietary Supplements by Military Personnel. Recent Survey Findings and Implications for Future Surveys of Dietary Supplement Use. Washington, DC: The National Academies Press; 2008:52.

7. Sobal J, Muncie H, Guyther J. Nutritional supplement use by patients in a rural family practice. J Am Coll Nutr. 1986;5:313-316.

8. Sobal J, Daly MP. Vitamin/mineral supplement use among general practice patients in the United Kingdom. Fam Pract. 1990;7:181-183.

9. Ranelli P, Dickerson R, White K. Use of vitamin and mineral supplements by pharmacy students. Am J Hosp Pharm. 1993;50:674-678.

10. Bailey R, Gahche J, Miller P, et al. Why US adults use dietary supplements. JAMA Intern Med. 2013;4:1-7.

11. Carroll D, Ring C, Suter M, et al. The effects of an oral multivitamin combination with calcium, magnesium, and zinc on psychological well-being in healthy young male volunteers: a double-blind placebo-controlled trial. Psychopharmacology (Berl). 2000; $150: 220-225$

12. Kennedy DO, Veasey R, Watson A, et al. Effects of high-dose B vitamin complex with vitamin $\mathrm{C}$ and minerals on subjective mood and performance in healthy males. Psychopharmacology (Berl). 2010;211:55-68.

13. Kennedy D, Veasey R, Watson A, et al. Vitamins and psychological functioning: a mobile phone assessment of the effects of a $\mathrm{B}$ vitamin complex, vitamin $\mathrm{C}$ and minerals on cognitive performance and subjective mood and energy. Hum Psychopharmacol. 2011;26:338-347.

14. Benton D, Haller J, Fordy J. Vitamin supplementation for 1 year improves mood. Neuropsychobiology. 1995;32:98-105.

15. Long S, Benton D. Effects of vitamin and mineral supplementation on stress, mild psychiatric symptoms, and mood in nonclinical samples: a meta-analysis. Psychosom Med. 2013;75:144-153.

16. Lyle B, Mares-Perlman J, Klein B, et al. Supplement users differ from nonusers in demographic, lifestyle, dietary and health characteristics. J Nutr. 1998;128:2355-2362.

17. Bender M, Levy A, Schucker R, et al. Trends in prevalence and magnitude of vitamin and mineral supplement usage and correlation with health status. J Am Diet Assoc. 1992;92:1096-1101.

18. Salovey P, Birnbaum D. Influence of mood on health-relevant cognitions. J Pers Soc Psychol. 1989;57:539-551.

19. Kobau R, Safran M, Zack M, et al. Sad, blue or depressed days, health behaviors and health-related quality of life, Behavioral Risk Factor Surveillance System, 1995-2000. Health Qual Life Outcomes. 2004;2:1-8

20. Army Regulation AR 70-25. Washington, DC: Headquarters, Department of the Army; 1990. Available at: http://www.apd.army.mil/pdffiles/r70_25. pdf. Accessed January 14, 2014.

21. Woodruffe-Peacock C, Turnbull G, Johnson A, et al. The quick mood scale: development of a simple mood assessment scale for clinical pharmacology studies. Hum Psychopharmacol Clin Exp. 1998;13:53-58.

22. Benton D, Donohoe R. The effects of nutrients on mood. Public Health Nutr. 1999;2:403-409.

23. Morrison L, Gizis F, Shorter B. Prevalent use of dietary supplements among people who exercise at a commercial gym. Int J Sport Nutr Exerc Metab. 2004:14:481-492.

24. Goston J, Correia M. Intake of nutritional supplements among people exercising in gyms and influencing factors. Nutrition. 2010;26:604-611.

25. Bianco A, Mammina C, Paoli A, et al. Protein supplementation in strength and conditioning adepts: knowledge, dietary behavior and practice in Palermo, Italy. J Int Soc Sports Nutr. 2011;8:1-6.

26. Pasiakos S. Military Relevance: Protein Supplementation in Warfighters. Department of Defense Center Alliance for Dietary Supplements Research 
Symposium: Efficacy and Safety of Protein Supplements for US Armed Forces Personnel; Natick, MA; 2012.

27. Pope H, Katz D. Psychiatric and medical effects of anabolic-androgenic steroid use. A controlled study of 160 athletes. Arch Gen Psychiatry. 1994;51:375-382.

28. Parrott A, Choi P, Davies M. Anabolic steroid use by amateur athletes: effects upon psychological mood states. J Sports Med Phys Fitness. 1994;34:292-298.

29. Ip E, Lu D, Barnett M, et al. Psychological and physical impact of anabolic-androgenic steroid dependence. Pharmacotherapy. 2012;32:910-919.
30. Kanayama G, Hudson J, Pope H. Illicit anabolic-androgenic steroid use. Horm Behav. 2010;58:111-121.

31. Hartgens F, Kuipers H. Effects of androgenic-anabolic steroids in athletes. Sports Med. 2004;34:513-554.

32. Chiou W, Chao-Chin Y, Chin-Sheng W. Ironic effects of dietary supplementation: illusory invulnerability created by taking dietary supplements licenses health-risk behaviors. Psychol Sci. 2011;22: 1081-1086.

33. Bandura A. Perceived self-efficacy in health-promoting behavior. In: Self-efficacy: The Exercise of Control. 4th ed. New York: WH Freeman and Company; 1997:279-318. 